EXTENDED REPORT

\title{
Infliximab improves signs and symptoms of psoriatic arthritis: results of the IMPACT 2 trial
}

\author{
C Antoni, G G Krueger, K de Vlam, C Birbara, A Beutler, C Guzzo, B Zhou, L T Dooley, \\ A Kavanaugh, for the IMPACT 2 investigators
}

See end of article for authors' affiliations

Correspondence to: Dr A Kavanaugh, Center for Innovative Therapy, Division of Rheumatology, Allergy and Immunology, University of California at San Diego, 9500 Gilman Drive, La Jolla, CA 920930943, USA; akavanaugh@ ucsd.edu

Accepted 16 January 2005 Published Online First 27 January 2005
Objectives: To evaluate further in a phase III, double blind trial the efficacy of infliximab in patients with active psoriatic arthritis (PsA), as observed in the smaller IMPACT trial.

Methods: 200 patients with active PsA unresponsive to previous treatment were randomised to infusions of infliximab $5 \mathrm{mg} / \mathrm{kg}$ or placebo at weeks $0,2,6,14$, and 22. Patients with inadequate response entered early escape at week 16. The primary measure of clinical response was ACR20. Other measures included Psoriatic Arthritis Response Criteria (PsARC), Psoriasis Area and Severity Index (PASI), and dactylitis and enthesopathy assessments.

Results: At week $14,58 \%$ of patients receiving infliximab and $11 \%$ of those receiving placebo achieved an ACR20 response and $77 \%$ of infliximab patients and $27 \%$ of placebo patients achieved PsARC (both $\mathrm{p}<0.001)$. Among the $85 \%$ of patients with at least $3 \%$ body surface area psoriasis involvement at baseline, 53/83 (64\%) patients receiving infliximab had at least $75 \%$ improvement in PASI compared with $2 / 87(2 \%)$ patients receiving placebo at week $14(p<0.001)$. These therapeutic effects were maintained through the last evaluation (week 24). Fewer infliximab patients than placebo patients had dactylitis at week 14 (18\% v 30\%; $p=0.025)$ and week 24 (12\% v 34\%; $p<0.001)$. Fewer infliximab patients (22\%) than placebo patients $(34 \%)$ had active enthesopathy at week $14(p=0.016)$; corresponding figures at week 24 were $20 \%$ and $37 \%$ ( $p=0.002)$. Infliximab was generally well tolerated, with a similar incidence of adverse events in each group.

Conclusions: Infliximab $5 \mathrm{mg} / \mathrm{kg}$ through 24 weeks significantly improved active PsA, including dactylitis and enthesopathy, and associated psoriasis.
$\mathrm{P}$ soriatic arthritis (PsA) is a chronic and inflammatory arthritis that occurs in association with skin psoriasis. The prevalence of psoriasis in the general population is about $1-3 \%,{ }^{2}$ and about $6-42 \%$ of patients with psoriasis develop PsA. ${ }^{3}{ }^{4}$ In the United States, an estimated 4.5 million adults have psoriasis and about 1 million have PsA. Interactions between $\mathrm{T}$ cells and monocytes/macrophages, the primary source of proinflammatory cytokines, including tumour necrosis factor $\alpha(\mathrm{TNF} \alpha)$, have an important role in the pathogenesis of PsA. Increased levels of TNF $\alpha$ have been detected in joint fluid and in psoriatic skin lesions in patients with PsA. ${ }^{67}$ The effects of $\mathrm{TNF} \alpha$ inhibition in psoriasis and PsA have been studied extensively with etanercept, a soluble TNF receptor antagonist, ${ }^{89}$ and infliximab, an anti-TNF $\alpha$ monoclonal antibody. ${ }^{10-17}$

In patients with PsA, data from several published studies suggest that infliximab provides fast and dramatic improvement in both arthritis and psoriasis. Results of these studies indicate that infliximab, with or without concomitant disease modifying antirheumatic drugs (DMARDs), may be an appropriate treatment for arthritis and skin lesions in patients with PsA. ${ }^{10-15}$ Data from the first double blind trial of infliximab in PsA (IMPACT), in which 104 patients were studied over 1 year, confirmed the efficacy of infliximab in PsA. ${ }^{16}$

This study, IMPACT 2, was undertaken to examine the efficacy and safety of infliximab in a larger patient group with active PsA and associated psoriasis. In addition to assessing the improvement in arthritis and psoriasis, IMPACT 2 evaluated the efficacy of infliximab in the treatment of two characteristic features of PsA, dactylitis and enthesopathy, as well as the effect of treatment on the quality of life in patients with this disabling condition.

\section{METHODS}

\section{Eligibility}

Two hundred adult patients with active PsA diagnosed at least 6 months before the first infusion of study drug were enrolled in this study. Active articular disease was defined as five or more swollen joints and five or more tender joints and either C reactive protein (CRP) levels of at least $15 \mathrm{mg} / \mathrm{l}$ and/ or morning stiffness lasting 45 minutes or longer. Patients were required to have had an inadequate response to current or previous DMARDs or non-steroidal anti-inflammatory drugs (NSAIDs). In addition, patients had to have active plaque psoriasis with at least one qualifying target lesion at least $2 \mathrm{~cm}$ in diameter. Patients also were required to have a negative test for rheumatoid factor in their serum.

Patients were excluded from this study if they had evidence of latent or active tuberculosis (that is, they had to have clear chest $x$ ray findings and a negative purified protein derivative skin test); had chronic or clinically significant infection, malignancy, or congestive heart failure; or if they had used TNF $\alpha$ inhibitors previously. Concomitant methotrexate (MTX) treatment (up to $25 \mathrm{mg} /$ week) was allowed at least 3 months before the first infusion and was maintained at a stable dose for at least 4 weeks before the

Abbreviations: ACR, American College of Rheumatology; AEs, adverse events; ALT, alanine aminotransferase; ANA, antinuclear antibody; AST, aspartate aminotransferase; BSA, body surface area; CRP, $C$ reactive protein; DMARDs, disease modifying antirheumatic drugs; dsDNA double stranded DNA; HAQ, Health Assessment Questionnaire; MTX methotrexate; NSAIDs, non-steroidal anti-inflammatory drugs; PASI, Psoriasis Area and Severity Index; PsA, psoriatic arthritis; PsARC, Psoriatic Arthritis Response Criteria; RA, rheumatoid arthritis; SF-36, Short Form-36; TNF $\alpha$, tumour necrosis factor $\alpha$, VAS, visual analogue scale 


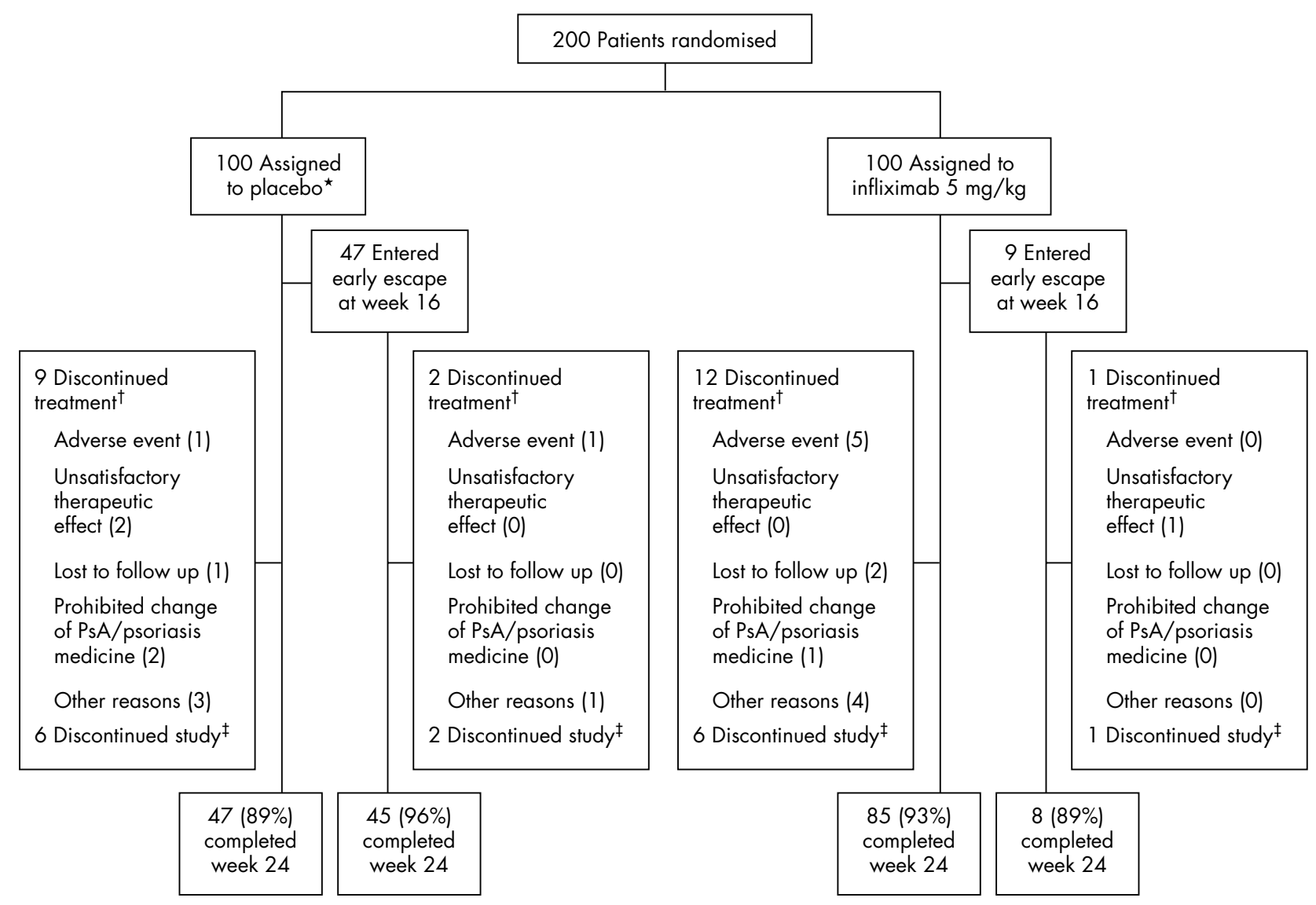

Figure 1 Summary of patient disposition, including the number of patients who were randomised to each treatment, entered early escape, discontinued treatment, and/or completed the study, in a controlled trial of infliximab and placebo in patients with PsA. *Three patients in the placebo group received infliximab at the first infusion in error and were not included in the safety analysis in the placebo group; tpatients who discontinued treatment remained in the study and returned for evaluations; fall patients who discontinued the study are counted in the total patients who discontinued treatment.

first infusion. Oral corticosteroid use was permitted at a stable dose equivalent to no more than $10 \mathrm{mg}$ prednisone a day. The use of DMARDs (other than MTX) or intra-articular corticosteroids was prohibited within 4 weeks before the first infusion, and DMARD use other than MTX was not allowed during the trial. Concurrent use of topical or systemic drugs/ treatments for psoriasis was not permitted during the study, with the exception of low potency topical corticosteroids on the face or groin.

\section{Study design}

This study was conducted at 36 centres: 19 in the US, 9 in Europe, and 8 in Canada. The first patient was enrolled on 20 December 2002, and the last patient completed the week 24 visit on 22 January 2004. Institutional Review Boards at the participating sites approved the study, and written informed consent was obtained from all patients before any protocolspecific procedures were performed.

This was a phase III, double blind, placebo controlled, randomised, parallel group study, in which patients were randomly assigned in a 1:1 ratio to receive infusions of either placebo or infliximab $5 \mathrm{mg} / \mathrm{kg}$ at weeks 0,2 , and 6 followed by maintenance dosing at weeks 14 and 22. Randomisation was stratified by investigational site and baseline MTX use and was performed using a dynamic patient allocation algorithm. To offer active treatment to patients randomised to placebo, any patient with $<10 \%$ improvement from baseline in both swollen and tender joint counts entered early escape and received infliximab $5 \mathrm{mg} / \mathrm{kg}$ at weeks 16,18 , and 22. To maintain the blinding, patients randomised to infliximab who had $<10 \%$ improvement received additional placebo infusions at weeks 16 and 18. Patients were assigned to this early escape using a blinded procedure that was part of an interactive patient allocation algorithm so that the option for early escape was not at the discretion of the patient or the physician.

\section{Study agent}

The study drug was prepared by an unblinded research pharmacist. Infliximab (Remicade; Centocor, Malvern, PA) was supplied in single-use $20 \mathrm{ml}$ vials containing $100 \mathrm{mg}$ of the lyophilised powder. Placebo was identically formulated except that it did not contain infliximab. Study drug infusion was started within 3 hours of reconstitution. The infusion solution was administered by blinded investigators over 2 hours.

\section{Study procedures and evaluations}

The primary efficacy assessment included components of the American College of Rheumatology (ACR) core set, which was developed originally for rheumatoid arthritis. ${ }^{18}$ These components were assessed at weeks 2, 6, 14, and 24 . Additional efficacy response evaluations, which were assessed at most visits from screening through week 24, included Psoriatic Arthritis Response Criteria (PsARC) ${ }^{19}$ and duration of morning stiffness (minutes) during the previous week. In addition, the following were assessed at weeks 0,14 , and 24: the presence of dactylitis in the hands and feet; the 
Table 1 Baseline characteristics of the patients*

\begin{tabular}{|c|c|c|}
\hline & Placebo & $\begin{array}{l}\text { Infliximab } \\
5 \mathrm{mg} / \mathrm{kg}\end{array}$ \\
\hline Patients randomised ( $\mathrm{n}$ ) & 100 & 100 \\
\hline Female sex $(\%)$ & 49 & 29 \\
\hline Age (years) & $46.5(11.3)$ & $47.1(12.8)$ \\
\hline \multicolumn{3}{|l|}{ PsA subtype (\%) } \\
\hline Arthritis involving distal interphalangeal joints & 23 & 26 \\
\hline Arthritis mutilans & 2 & 1 \\
\hline Asymmetric peripheral arthritis & 22 & 18 \\
\hline Polyarticular arthritis & 47 & 53 \\
\hline Spondylitis with peripheral arthritis & 6 & 2 \\
\hline PsA duration (years) & $7.5(7.8)$ & $8.4(7.2)$ \\
\hline \multicolumn{3}{|l|}{ ACR component } \\
\hline Number of swollen joints (0-66) & $14.4(8.9)$ & $13.9(7.9)$ \\
\hline Number of tender joints $(0-68)$ & $25.1(13.3)$ & 24.6 (14.1) \\
\hline CRP (mg/l) & $23(34)$ & $19(21)$ \\
\hline Physician's global assessment of disease activity (VAS; $0-10 \mathrm{~cm}$ ) & $5.9(1.7)$ & $5.5(1.8)$ \\
\hline Patient's global assessment of disease activity (VAS; $0-10 \mathrm{~cm}$ ) & $5.9(2.2)$ & $5.4(2.1)$ \\
\hline Patient's assessment of pain (VAS; $0-10 \mathrm{~cm}$ ) & $5.9(2.3)$ & $5.6(2.1)$ \\
\hline $\mathrm{HAQ}$ disability index (0-3) & $1.1(0.6)$ & $1.1(0.6)$ \\
\hline Duration of morning stiffness (0-1440 $\mathrm{min}$ ) & $183.4(308.8)$ & $216.0(376.0)$ \\
\hline Patients with 1 or more dactylitis digits (\%) & 41 & 40 \\
\hline Patients with enthesopathy (\%) & 35 & 42 \\
\hline \multicolumn{3}{|l|}{ Psoriasis evaluation } \\
\hline Patients with $\geqslant 3 \%$ BSA affected with psoriasis (\%) & 87 & 83 \\
\hline PASI score (0-72) & $10.2(9.0)$ & $11.4(12.7)$ \\
\hline Target lesion score (0-12) & $6.2(1.9)$ & $5.9(2.2)$ \\
\hline \multicolumn{3}{|l|}{ SF-36 score } \\
\hline Physical component (0-100) & $31.0(9.0)$ & $33.0(9.4)$ \\
\hline Mental component (0-100) & 47.0 (11.9) & 45.5 (11.9) \\
\hline \multicolumn{3}{|l|}{ Baseline drug } \\
\hline Patients taking MTX (\%) & 45 & 47 \\
\hline Patients taking oral corticosteroids (\%) & 10 & 15 \\
\hline Patients taking NSAIDs (\%) & 73 & 71 \\
\hline
\end{tabular}

presence/absence of enthesopathy in the feet; and the Short Form-36 (SF-36) questionnaire.

The definition of severity of psoriasis at baseline was based on the body surface area (BSA) affected: mild ( $<5 \%$ BSA), moderate $(5 \%$ to $<10 \%$ BSA), and severe ( $\geqslant 10 \%$ BSA). In patients with at least 3\% BSA psoriasis involvement at baseline, psoriasis activity was assessed using the Psoriasis Area and Severity Index (PASI) at baseline and weeks 2, 6,
14 , and 24. PASI is a composite score, ranging from 0 to 72 , used for assessing and grading the severity of psoriatic lesions and their response to treatment. PASI includes assessments of the extent of skin involvement, erythema, plaque thickness, and the degree of scaling. ${ }^{20}$ In addition, the target lesion score (erythema, plaque induration, and scaling rated on a scale of 0-4 each) was assessed at weeks 0,14 , and 24 in all patients, irrespective of baseline PASI scores.
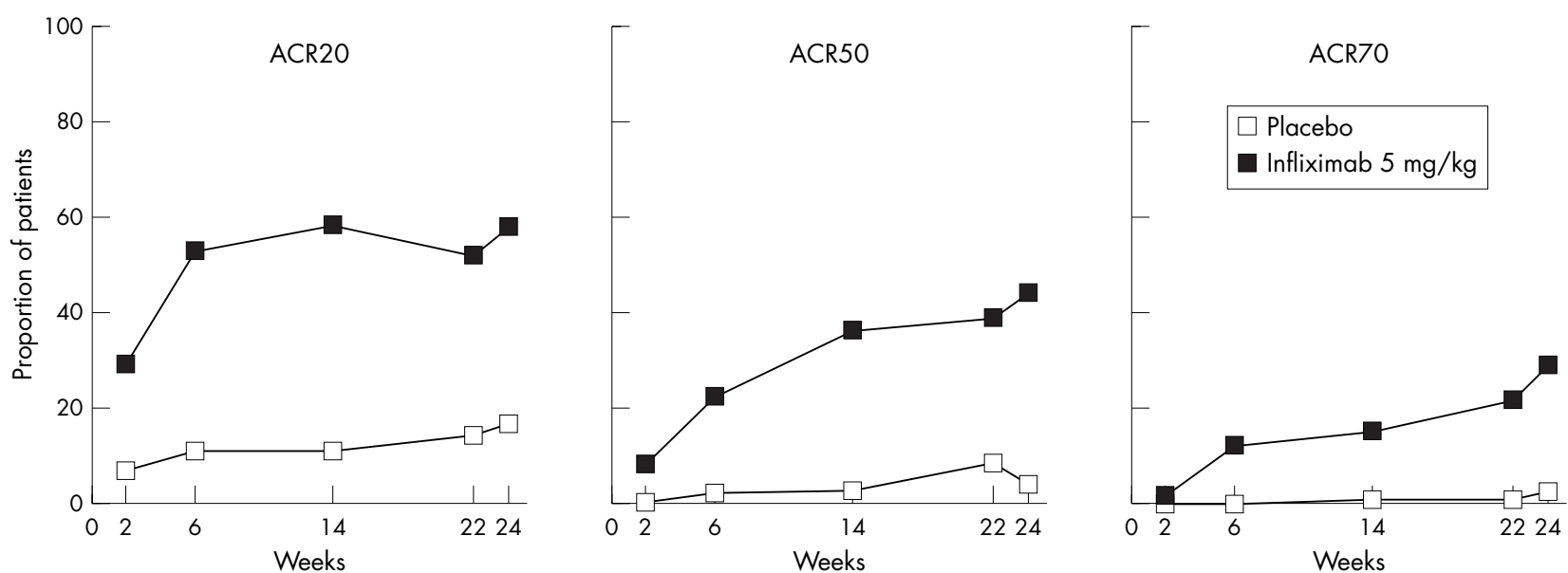

Figure 2 Time pattern of arthritis response, as measured by various degrees of American College of Rheumatology (ACR) response in patients with PsA treated with infliximab or placebo. 
Table 2 Clinical responses at weeks 14 and 24*

\begin{tabular}{|c|c|c|c|c|c|c|}
\hline & \multicolumn{3}{|l|}{ Week 14} & \multicolumn{3}{|l|}{ Week 24} \\
\hline & Placebo & $\begin{array}{l}\text { Infliximab } \\
5 \mathrm{mg} / \mathrm{kg}\end{array}$ & p Value & Placebo & $\begin{array}{l}\text { Infliximab } \\
5 \mathrm{mg} / \mathrm{kg}\end{array}$ & p Value \\
\hline Patients randomised (n) & 100 & 100 & & 100 & 100 & \\
\hline \multicolumn{7}{|l|}{ ACR criteria } \\
\hline $20 \%$ Improvement $(\%) \dagger$ & 11 & 58 & $<0.001$ & 16 & 54 & $<0.001$ \\
\hline $50 \%$ Improvement $(\%) \dagger$ & 3 & 36 & $<0.001$ & 4 & 41 & $<0.001$ \\
\hline $70 \%$ Improvement $(\%) \dagger$ & 1 & 15 & $<0.001$ & 2 & 27 & $<0.001$ \\
\hline Achieving PsARC (\%) & 27 & 77 & $<0.001$ & 32 & 70 & $<0.001$ \\
\hline \multicolumn{7}{|l|}{ Percentage improvement† } \\
\hline Number of swollen joints & $-3.5(68.9)$ & $41.5(81.1)$ & $<0.001$ & $23.5(39.8)$ & $58.0(45.3)$ & $<0.001$ \\
\hline Number of tender joints & $-13.0(78.7)$ & $47.4(46.6)$ & $<0.001$ & $14.9(36.5)$ & $54.1(45.2)$ & $<0.001$ \\
\hline CRP & $-5.7(64.0)$ & $33.8(66.6)$ & $<0.001$ & $-7.0(55.0)$ & $34.7(67.5)$ & $<0.001$ \\
\hline Physician's global assessment of disease activity (VAS) & $12.5(45.7)$ & $51.7(60.5)$ & $<0.001$ & $18.0(55.9)$ & $57.3(46.8)$ & $<0.001$ \\
\hline Patient's global assessment of disease activity (VAS) & $1.3(65.0)$ & $39.7(65.7)$ & $<0.001$ & $7.2(45.4)$ & $35.1(74.4)$ & $<0.001$ \\
\hline Patient's assessment of pain (VAS) & $-11.8(109.8)$ & $39.6(56.1)$ & $<0.001$ & $-10.0(114.2)$ & $37.4(54.2)$ & $<0.001$ \\
\hline $\mathrm{HAQ}$ disability index & $-18.4(90.5)$ & $48.6(43.3)$ & $<0.001$ & $-19.4(102.8)$ & $46.0(42.5)$ & $<0.001$ \\
\hline Duration of morning stiffness & $-121.6(694.7)$ & $42.2(101.6)$ & $<0.001$ & $-152.0(882.6)$ & $43.1(103.9)$ & $<0.001$ \\
\hline Patients with $\geqslant 1$ dactylitis digits (\%) & 30 & 18 & 0.025 & 34 & 12 & $<0.001$ \\
\hline Patients with enthesopathy (\%) & 34 & 22 & 0.016 & 37 & 20 & 0.002 \\
\hline \multicolumn{7}{|l|}{ PASI response } \\
\hline Patients with $\geqslant 3 \%$ BSA affected with psoriasis (baseline) & 87 & 83 & & 87 & 83 & \\
\hline$\geqslant 50 \%$ Improvement \%) $\dagger$ & 9 & 82 & $<0.001$ & 8 & 75 & $<0.001$ \\
\hline$\geqslant 75 \%$ Improvement $(\%) \dagger$ & 2 & 64 & $<0.001$ & 1 & 60 & $<0.001$ \\
\hline$\geqslant 90 \%$ Improvement $(\%) \dagger$ & 0 & 41 & $<0.001$ & 0 & 39 & $<0.001$ \\
\hline Percentage improvement in target lesion score $†$ & $-0.3(37.4)$ & $65.6(35.9)$ & $<0.001$ & $-1.0(40.1)$ & $64.2(43.9)$ & $<0.001$ \\
\hline \multicolumn{7}{|l|}{ Change in SF-36† } \\
\hline Physical component & $1.1(8.4)$ & $9.1(9.3)$ & $<0.001$ & $1.3(8.2)$ & $7.7(9.8)$ & 0.001 \\
\hline Mental component & $-1.2(9.3)$ & $3.8(11.1)$ & $<0.001$ & $0.4(11.6)$ & 3.9 (11.9) & 0.047 \\
\hline
\end{tabular}

\section{Safety evaluations}

Safety evaluations, including the monitoring of adverse events (AEs) and routine laboratory tests of haematology and chemistry measures, were performed at every visit through week 24 . Blood samples were obtained to determine the presence of antibodies to infliximab using previously described enzyme immunoassay methods ${ }^{21}$ before infusion at baseline and at week 22. Additionally, blood samples were obtained to determine antinuclear antibodies (ANAs; titre of $1 / 160$ or more was considered positive) using the indirect fluorescent antibody test on Hep-2 cells before infusion at baseline and week 24. Among the samples positive for ANAs, the number that were positive for antibodies to double stranded DNA (anti-dsDNA) are reported..$^{22} 23$

\section{Statistical methods}

The primary end point was the achievement of at least $20 \%$ improvement according to ACR criteria (ACR20) at week 14. The sample size of 200 patients was chosen to ensure an adequate safety evaluation. This sample size also ensured that there was $90 \%$ power to detect a significant difference in the proportion of ACR20 responders between the two treatment groups using a $\chi^{2}$ test at a significance level of 0.05 , assuming $20 \%$ and $42 \%$ of patients in the placebo and infliximab treatment groups, respectively, achieved an ACR20 response. To confirm these power calculations, results of the $\chi^{2}$ test were simulated using the Cochran-Mantel-Haenszel test stratified by baseline MTX use; the power ranged from 0.9 to 0.99 for all simulated cases.

The Cochran-Mantel-Haenszel $\chi^{2}$ test stratified by baseline MTX use was used to analyse the primary end point and other secondary end points with categorical data. Continuous data were compared with a two sided F test using an analysis of variance method with baseline MTX use as a factor on the van der Waerden normal scores. ${ }^{24}$

Subjects with missing ACR20 and PsARC data at weeks 14 and 24 were considered non-responders in these analyses, and data for subjects with missing PASI75 at these times were imputed with last observation carried forward. At week 24, early escape subjects were treated as non-responders for ACR20, ACR50, ACR70, and PsARC; the last observation before early escape at week 16 was carried forward for other assessments.

The primary efficacy and selected secondary efficacy analyses were based on the treatment to which patients were randomised (intention to treat), while safety (AEs and postbaseline laboratory abnormalities) analyses were based on the actual treatment received and included patients who received at least one study infusion. Safety is reported through week 24 for the combined infliximab group, which included all patients randomised to infliximab as well as all patients randomised to placebo who entered early escape at week 16 or received infliximab in error.

\section{RESULTS}

\section{Patient disposition and baseline characteristics}

Of the 320 patients who were screened for eligibility, 200 were enrolled; of these, 185 (93\%) completed the study at week 24 (fig 1). Figure 1 presents the specific reasons for discontinuation.

The demographic and baseline disease characteristics of the placebo and infliximab groups were generally well balanced (table 1). As shown by the baseline levels for the ACR components, patients enrolled in this trial had active 
disease. A substantial proportion of the patients had dactylitis or enthesopathy, or both. Most patients (170/200 $(85 \%))$ had at least 3\% BSA psoriasis involvement. When the baseline BSA was considered, the vast majority $(>70 \%)$ had moderate or severe psoriasis. Patients' baseline SF-36 physical and mental component summary scores indicated reduced quality of life in the enrolled patients compared with the general American population, ${ }^{25}$ and their Health Assessment Questionnaire (HAQ) scores indicated impaired physical function. Similar proportions of patients were receiving MTX at baseline $(45 \%$ and $47 \%$ in the placebo and infliximab groups, respectively) at a mean dose of $15 \mathrm{mg} /$ week in the placebo group and $16 \mathrm{mg} /$ week in the infliximab group.

\section{Efficacy}

Arthritis response

Figure 2 shows that the ACR response to infliximab treatment was evident as early as week 2 and responses were maintained throughout the study. Significantly $(p<0.001)$ higher proportions of patients treated with infliximab achieved an ACR20 response at week 14 (58\%) and week $24(54 \%)$ than did patients treated with placebo ( $11 \%$ and $16 \%$ at weeks 14 and 24 , respectively). At week 14 $36 \%$ of patients treated with infliximab achieved an ACR50 response and 15\% achieved an ACR70 response, compared with $3 \%$ and $1 \%$, respectively, of patients treated with placebo $(\mathrm{p}<0.001$; fig 2). ACR50 and ACR70 responses increased from week 14 to week 24 , at which time $41 \%$ of patients treated with infliximab achieved an ACR50 response and 27\% achieved an ACR70 response, compared with $4 \%$ and $2 \%$, respectively, of patients treated with placebo $(\mathrm{p}<0.001$; table 2).

Twenty eight of $47(60 \%)$ patients receiving MTX at baseline (MTX users) and 30/53 (57\%) patients not receiving MTX (MTX non-users) achieved an ACR20 response at week 14. Fewer MTX users than MTX non-users achieved an ACR50 response $(28 \% v 43 \%)$ and ACR70 response $(9 \% v$ $21 \%$ ) at week 14 . Results at week 24 were similar between MTX users and non-users for ACR20 response (57\% v 51\%), ACR50 response $(43 \% v 40 \%)$, and ACR70 response $(21 \% v$ $32 \%)$. The generally lower ACR50 and ACR70 responses among MTX users are probably related to the small number of patients included in these analyses and should be interpreted with caution. In general, the concomitant use of MTX did not appear to affect efficacy among patients in the infliximab group. As with the overall study group, the differences in ACR response between the infliximab and placebo groups were significant within both the MTX user and MTX non-user subgroups (data not shown).

Results for assessments of joint disease other than the ACR core set confirmed the efficacy of infliximab. Significant improvements from baseline to weeks 14 and 24 were seen for the individual components of the ACR20 among patients in the infliximab group compared with those in the placebo group (table 2). At week 14, 77\% of patients treated with infliximab had improved according to the PsARC, compared with $27 \%$ of patients treated with placebo $(\mathrm{p}<0.001)$; similar findings were seen at week $24(70 \%$ v $32 \%$; $<<0.001)$. Although similar numbers of patients treated with infliximab and placebo ( $41 \%$ and $40 \%$, respectively) had dactylitis of one or more digits at baseline, fewer patients treated with infliximab had digits with dactylitis in comparison with patients treated with placebo at week 14 (18\% $v 30 \%$; $\mathrm{p}=0.025)$ and week $24(12 \% \vee 34 \% ; \mathrm{p}<0.001)$. In addition, although $42 \%$ and $35 \%$ of patients in the infliximab and placebo groups, respectively, had enthesopathy at baseline, a significantly lower proportion of patients treated with infliximab had enthesopathy compared with patients treated with placebo at both week $14(22 \% v 34 \% ; \mathrm{p}=0.016)$ and week $24(20 \%$ v 37\%; $\mathrm{p}=0.002)$.

\section{Skin response}

Among the 170 patients who had psoriasis affecting at least $3 \%$ of the BSA at baseline, significantly higher proportions of patients treated with infliximab had at least 50\%, 75\%, and $90 \%$ improvement in the PASI from baseline to week 14 in comparison with placebo treated patients $(\mathrm{p}<0.001$; fig 3$)$. The proportion of patients with at least a $75 \%$ improvement in the PASI was significantly higher in the infliximab group than in the placebo group at week $14(53 / 83(64 \%) \vee 2 / 87$ $(2 \%) ; \mathrm{p}<0.001)$ and week $24(50 / 83(60 \%) \vee 1 / 87 \quad(1 \%)$; $\mathrm{p}<0.001)$. Findings at week 14 were similar to those at week 24 for all PASI results (table 2). Figure 3 shows that the skin response to infliximab treatment was evident as early as week 2 and improvement was maintained through week 24 . Patients treated with infliximab also had a significant $(\mathrm{p}<0.001)$ improvement from baseline to week 14 in the target lesion score relative to patients treated with placebo $(65.6 \% v-0.3 \% ; \mathrm{p}<0.001)$, with response maintained at week 24 (table 2).

\section{Effect on physical and mental function}

The physical and mental components of the SF-36 summary scores were significantly improved from baseline to week 14 in patients treated with infliximab $(\mathrm{p}<0.001$; table 2$)$ relative
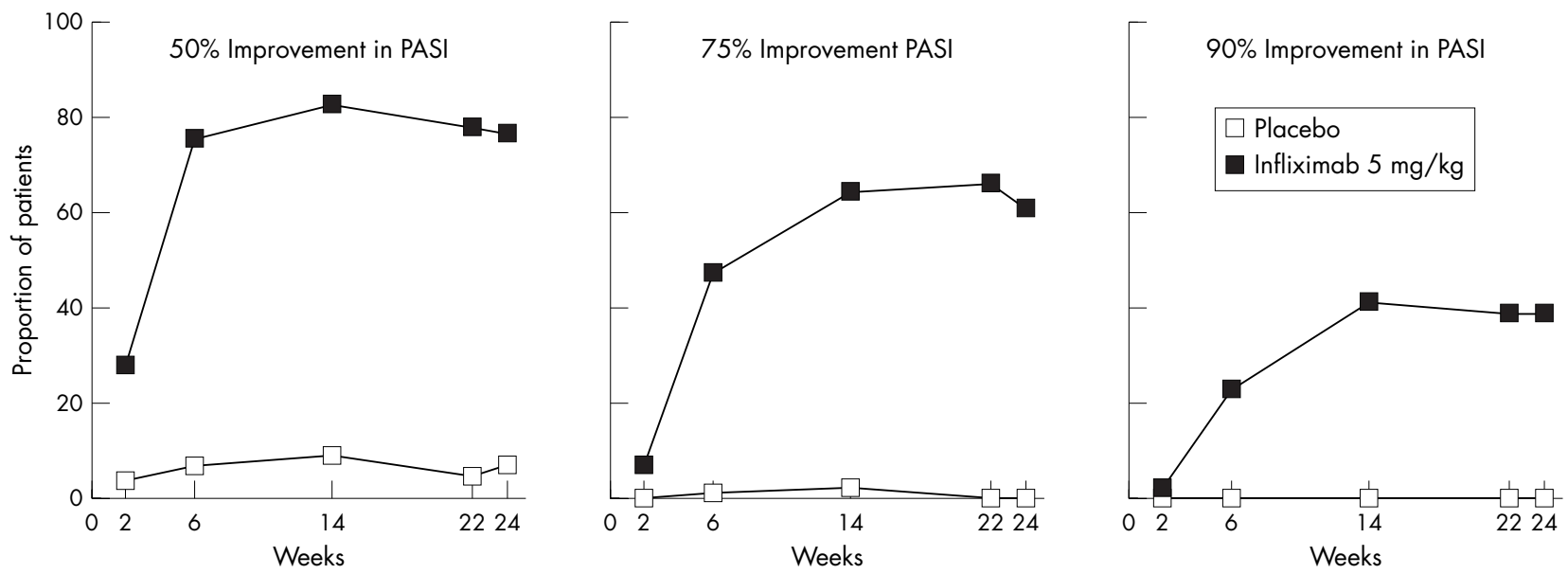

Figure 3 Skin response over time, as measured by various degrees of the PASI improvement in patients with PsA treated with infliximab or placebo. 


\begin{tabular}{lcc} 
Table 3 No (\%) of AEs through week 24 & \\
\hline & $\begin{array}{l}\text { Placebo } \\
(\mathbf{n}=97)\end{array}$ & $\begin{array}{l}\text { Combined } \\
(\mathbf{n}=150)\end{array}$ \\
\hline Any AE & $65(67)$ & $100(67)$ \\
Common AEs by WHOART preferred term† & $14(14)$ & $15(10)$ \\
Upper respiratory tract infection & $5(5)$ & $9(6)$ \\
Headache & $1(1)$ & $9(6)$ \\
Increased ALT & $4(4)$ & $8(5)$ \\
Pharyngitis & $4(4)$ & $8(5)$ \\
Sinusitis & $5(5)$ & $6(4)$ \\
Dizziness & $1(1)$ & $6(4)$ \\
AEs leading to withdrawalł & $6(6)$ & $13(9)$ \\
Serious AEs & $6(6)$ & $11(7)$ \\
Infusion reactions &
\end{tabular}

*The combined group included all patients randomised to infliximab and all patients randomised to placebo who entered early escape at week 16 or incorrectly received infliximab; †common AEs are AEs with event rate $\geqslant 5 \%$ in the placebo group or the infliximab group. AEs are sorted by decreasing incidence in the infliximab column; ‡an AE was the primary reason for withdrawal in these patients.

ALT, alanine aminotransferase; AST, aspartate aminotransferase.

to those treated with placebo. Results were similar for the physical $(p=0.001)$ and mental $(p=0.047)$ components at week 24. Furthermore, at week 14, the proportion of patients who achieved a clinically meaningful change in HAQ (that is, at least a 0.3 decrease) $)^{26}$ was significantly higher in the infliximab group than in the placebo group (59\% v 19\%; $\mathrm{p}<0.001)$; this response was sustained at week $24(52 \% \mathrm{v}$ $20 \% ; \mathrm{p}<0.001)$.

\section{Adverse events}

Infliximab was generally well tolerated through week 24 . The incidences of AEs, serious AEs, infections, and infusion reactions were similar between treatment groups (table 3 ). The percentage of patients who experienced AEs leading to withdrawal in the combined infliximab group was higher than that in the placebo group ( $4 \% \vee 1 \%)$.

Overall, few clinically significant abnormal laboratory findings were reported. Aminotransferase increases occurred more frequently in patients treated with infliximab than in those treated with placebo. Most of these increases were less than three times the upper limit of normal. Markedly abnormal alanine transaminase (ALT) and/or aspartate transaminase (AST) values (predefined as >150 IU/l and $\geqslant 100 \%$ increase from baseline) were reported in five patients in the combined infliximab group compared with no patients in the placebo group. All five patients discontinued study infusions. One patient was lost to follow up, but ALT/AST levels returned to normal or less than 1.5 times the upper limit of normal in all four patients for whom follow up data were available. None of these increases were associated with signs of liver failure. One of the five patients was receiving concomitant MTX.

Through week 24, no deaths occurred and no opportunistic infections, including tuberculosis, were reported. No congestive heart failure, demyelinating or new autoimmune disorders, serious infusion reactions, anaphylaxis, or delayed hypersensitivity reactions were reported. One patient treated with placebo developed a basal cell carcinoma of the skin. A small percentage $(4.5 \%)$ of patients in the combined infliximab group were positive through week 22 for antibodies to infliximab. Newly positive ANAs (defined by titre $\geqslant 1 / 160$ ) were detected in $9.9 \%$ of patients in the combined infliximab group compared with $2.6 \%$ in the placebo group. Newly positive anti-dsDNA antibodies were detected in three ANA positive patients treated with infliximab and no ANA positive patients treated with placebo. No patient developed a lupus-like condition.

\section{DISCUSSION}

One quarter of the patients with PsA are dissatisfied with the treatment they receive. ${ }^{5}$ The disease manifests first in relatively young patients (age 30-55 years), ${ }^{327}$ compared with other rheumatic diseases such as rheumatoid arthritis (RA), and is associated with impaired physical function, ${ }^{28}$ reduced quality of life, ${ }^{28}$ and increased mortality..$^{29} 30$ Therefore, PsA profoundly affects individual wellbeing and socioeconomic status. ${ }^{28-32}$ Some of the current treatments for PsA, including sulfasalazine, ${ }^{19}$ leflunomide, ${ }^{33}$ and etaner$\mathrm{cept}^{8}{ }^{9}$ have been well assessed; many of the other commonly used treatments have been adapted from treatment of RA, and their use in PsA is not supported by clinical trial data. Furthermore, the use of some traditional DMARDs can be associated with organ toxicity, and the incidence and severity of these toxicities may be different in patients with PsA than in patients with RA. ${ }^{34}{ }^{35}$ Considering the potentially disabling nature of PsA and the level of dissatisfaction with current treatments, there is a need for additional treatments. The results of the IMPACT 2 study demonstrate that infliximab is effective and well tolerated for the treatment of both the joint and skin components of PsA.

The patients enrolled in IMPACT 2 represented a disease population with well defined features of PsA, such as arthritis, psoriasis, and rheumatoid factor negative status. Patients in both treatment groups had characteristic features of PsA, including the presence of dactylitis and enthesopathy. All patients had psoriasis with substantial skin involvement, and psoriasis was frequently rated as moderate to severe as measured by baseline BSA involvement.

In this study infliximab was significantly more effective than placebo when evaluated using ACR20 response at week 14 (the primary end point) and was better for many other PsA evaluations, including ACR50, ACR70, individual ACR components, PsARC, and assessments of dactylitis and enthesopathy. Specifically, ACR50 and ACR70 responses were significantly greater in the infliximab group than in the placebo group by weeks 2 and 6, respectively, and continued to improve throughout the 24 week study. The substantial percentage of patients who achieved an ACR70 response $(27 \%)$ indicates that infliximab is highly effective in a significant number of patients. Further, concomitant use of MTX did not appear to affect the efficacy. Finally, two distinctive and common clinical manifestations of PsA, dactylitis and enthesopathy, which have not commonly been included as outcomes in PsA clinical studies, were present in a substantial proportion of patients at baseline and improved significantly at both week 14 and week 24 in patients receiving infliximab.

The concomitant and dramatic improvement in psoriasis in this study is noteworthy. Patients treated with infliximab experienced rapid, substantial, and sustained improvement in psoriasis, when measured by PASI improvement in patients with more significant disease and by target lesion score in those with less, as well as more, significant disease. As early as week 2 , the proportion of patients with at least a $75 \%$ improvement in PASI from baseline in the infliximab group was significantly greater than that in the placebo group. Marked improvement was seen by week 14 (64\%) and sustained through week $24(60 \%)$. Although this was not an active comparator study, when the PASI75 scores are compared with those achieved by similar patient groups receiving etanercept $25 \mathrm{mg}$ twice weekly in two randomised and controlled studies, the response to etanercept is less marked; only $26 \%$ and $23 \%$ of etanercept treated patients, respectively, achieved the PASI75 end point at weeks 12 and $24 .^{89}$ The results for the PASI response in IMPACT 2 were substantiated by the mean percentage improvement in target lesion score. Significantly, the efficacy results for all end 
points for improvement of both psoriasis and PsA for the IMPACT 2 study of 200 patients at 36 centres confirm those reported previously in the smaller IMPACT study of 104 patients at nine centres. ${ }^{16}$

In addition to the positive impact of infliximab on standard assessments of joint and skin disease, this study recorded an improvement in quality of life and physical function. Results of the SF-36 questionnaire indicated a significantly greater improvement in the physical and mental component summary scores from baseline to weeks 14 and 24 in the infliximab group than in the placebo group. Accordingly, HAQ results showed that patients in the infliximab group experienced improvement in physical function. Furthermore, the proportion of patients who achieved a clinically meaningful change in HAQ was significantly higher in the infliximab group than in the placebo group. These findings are especially relevant to patients with PsA, given the potentially debilitating nature of the disease and the psychosocial effect of the disease state in many patients with psoriasis. ${ }^{36}$

Infliximab was well tolerated through week 24, with generally similar AE profiles in the infliximab and placebo groups. Up to week 24, the overall incidences of AEs, serious AEs, infections, and infusion reactions were similar between the treatment groups. The type and incidence of infections were not notably different from those reported in previous studies of infliximab in other indications. ${ }^{37} 38$ Transient increases in ALT and AST values, which were not associated with concomitant significant increases in bilirubin or with other evidence of hepatotoxicity, were reported more commonly in the infliximab group than in the placebo group. Increases of aminotransferases have been seen previously with infliximab treatment in RA subjects. ${ }^{37} \mathrm{~A}$ comprehensive review of postmarketing data is currently under way. As with any new patient group, the relative significance of these increases in patients with PsA will require additional evaluation over the long term.

In summary, the results of the IMPACT 2 trial confirm that treatment with infliximab for up to 6 months is effective in patients with active PsA. Infliximab $5 \mathrm{mg} / \mathrm{kg}$, given at weeks $0,2,6$, and every 8 weeks thereafter through 24 weeks, reduced the clinical signs and symptoms of PsA, including dactylitis and enthesopathy, and improved psoriatic skin disease, physical function, and quality of life in this patient group. Treatment with infliximab was generally well tolerated, with an $\mathrm{AE}$ profile similar to that seen in other indications.

\section{ACKNOWLEDGEMENTS}

The IMPACT 2 study was funded by Centocor, Inc, in Malvern, Pennsylvania, USA and Schering-Plough in Kenilworth, NJ, USA. C Antoni, A Kavanaugh, and GG Krueger have received research support and served as consultants for Centocor, Inc. K de Vlam has served as a consultant for Centocor, Inc. A Beutler, C Guzzo, B Zhou, and L Dooley are employees of Centocor, Inc, Malvern, Pennsylvania, USA. C Birbara has received research support from Centocor, Inc. We acknowledge C Arnold of Centocor, Inc for her assistance in preparing this manuscript.

\section{Authors' affiliations \\ C Antoni, Friedrich Alexander University of Erlangen-Nürnberg, Erlangen, Germany \\ G G Krueger, University of Utah Health Sciences Center, Salt Lake City, UT, USA \\ K de Vlam, University Hospital Leuven, Leuven, Belgium \\ C Birbara, University of Massachusetts School of Medicine, Worcester, MA, USA \\ A Beutler, C Guzzo, B Zhou, L T Dooley, Centocor, Inc, Malvern, PA, USA}

A Kavanaugh, Division of Rheumatology, Allergy, and Immunology, University of California San Diego, La Jolla, CA, USA

Investigators for the Infliximab Multinational Psoriatic Arthritis Controlled Trial (IMPACT) 2 study include:

USA: Dr C Birbara, Worcester, Massachusetts; Dr EP Boling, Upland, California; $\operatorname{Dr} C$ Codding, Oklahoma City, Oklahoma; Dr JJ Fiechtner, Lansing, Michigan; Dr RM Fleischmann, Dallas, Texas; Dr SI Goodman, Delray Beach, Florida; Dr AB Gottlieb, New Brunswick, New Jersey; Dr DG Halter, Houston, Texas; Dr JL Harshbarger, Wilmington, North Carolina; Dr K Hobbs, Denver, Colorado; Dr A Kavanaugh, La Jolla, California; Dr SM Lourie, Greenbelt, Maryland; Dr P Mease, Seattle, Washington; Dr A Menter, Dallas, Texas; Dr DM Pariser, Norfolk, Virginia; Dr WJ Shergy, Huntsville, Alabama; Dr EL Siegel, Wheaton, Maryland; Dr ME Wenger, Lancaster, Pennsylvania; Dr DJ Wallace, Los Angeles, California.

Canada: Dr R Bissonnette, Montreal, Quebec; Dr J Carter Thorne, New Market, Ontario; Dr D Gladman, Toronto, Ontario; Dr E Keystone, Toronto, Ontario; Dr W Gulliver, St John's, New Foundland; Dr K Papp, Waterloo, Ontario; Dr Y Poulin, Quebec, Quebec; Dr L Rosoph, North Bay, Ontario.

Germany: Dr C Antoni, Erlangen; Dr GR Burmester, Berlin; Dr C Fiehn, Heidelberg; Dr J Sieper, Berlin; Dr J Wollenhaupt, Hamburg.

Belgium: Dr P Geusens, Diepenbeek; Dr R Westhovens, Leuven.

United Kingdom: Dr P Emery, Leeds; Dr B Kirkham, London.

\section{REFERENCES}

1 Biondi Oriente C, Scarpa R, Pucino A, Oriente P. Psoriasis and psoriatic arthritis. Dermatological and rheumatological co-operative clinical report. Acta Derm Venerol Suppl (Stockh) 1989;146:69-71.

2 Koo J. Population based epidemiologic study of psoriasis with emphasis on quality of life assessment. Dermatol Clin 1996;14:485-96

3 Shbeeb M, Uramoto KM, Gibson LE, O'Fallon WM, Gabriel SE. The epidemiology of psoriatic arthritis in Olmsted Country, Minnesto, USA, 19821991. J Rheumatol 2000;27:1247-50.

4 Green L, Meyers OL, Gordon W, Briggs B. Arthritis in psoriasis. Ann Rheum Dis 1981;40:366-9.

5 National Psoriasis Foundation. Benchmark survey on psoriasis and psoriatic arthritis. New National Psoriasis Foundation survey shows that psoriasis diminishes quality of life for millions. 2002. Available at http:// www.psoriasis.org/news/news/2001/200104_npfsurvey.php (accessed 14 February 2005).

6 Partsch G, Steiner G, Leeb BF, Dunky A, Broll H, Smolen JS. Highly increased levels of tumor necrosis factor-alpha and other proinflammatory cytokines in psoriatic arthritis synovial fluid. J Rheumatol 1997;24:518-23.

7 Danning CL, Illei GG, Hitchon C, Greer MR, Boumpas DT, Mclnnes IB. Macrophage-derived cytokine and nuclear factor $\kappa B$ p 65 expression in synovial membrane and skin of patients with psoriatic arthritis. Arthritis Rheum 2000;43:1244-56.

8 Mease PJ, Goffe BS, Metz J, VanderStoep A, Finck B, Burge DJ. Etanercept in the treatment of psoriatic arthritis and psoriasis: a randomized trial. Lancet 2000;356:385-90.

9 Mease PJ, Kivitz AJ, Burch FX, Siegel EL, Cohen SB, Ory P, et al. Etanercept treatment of psoriatic arthritis: safety, efficacy, and effect on disease progression. Arthritis Rheum 2004;50:2264-72.

10 Ogilvie AL, Antoni C, Dechant C, Manger B, Kalden JR, Schuler GS, et al. Treatment of psoriatic arthritis with antitumor necrosis factor-alpha antibody clears skin lesions of psoriasis resistant to treatment with methotrexate. $\mathrm{Br} J$ Dermatol 2001; 144:587-9.

11 Antoni C, Dechant C, Hanns-Martin Lorenz PD, Wendler J, Ogilvie A, Lueffl M, et al. Open-label study of infliximab treatment for psoriatic arthritis: clinical and magnetic resonance imaging measurements of reduction of inflammation. Arthritis Rheum 2002;47:506-12.

12 Van den Bosch F, Kruithof E, Baeten D, DeKeyser F, Mielants H, Veys EM. Effects of a loading dose regimen of three infusions of chimeric monoclonal antibody to tumor necrosis factor alpha (infliximab) in spondyloarthropathy: an open pilot study. Ann Rheum Dis 2000;59:428-33.

13 Kruithof E, Van den Bosch F, Baeten D, Herssens A, De Keyser F, Mielants H, et al. Repeated infusions of infliximab, a chimeric anti-TNF $\alpha$ monoclonal antibody, in patients with active spondyloarthropathy: one year follow up. Ann Rheum Dis 2002;61:207-12.

14 Salvarani C, Cantini F, Olivieri I, Macchioni P, Padula A, Niccoli L, et al. Efficacy of infliximab in resistant psoriatic arthritis. Arthritis Rheum 2003;49:541-5.

15 Feletar M, Brockbank JE, Schentag CT, Lapp V, Gladman DD. Treatment of refractory psoriatic arthritis with infliximab: a 12 month observational study of 16 patients. Ann Rheum Dis 2004;63:156-61.

16 Antoni CE, Kavanaugh A, Kirkham B, Tutuncu Z, Burmester GR, Schneider U, et al. Sustained benefits of infliximab therapy for dermatologic and articular manifestations of psoriatic arthritis: results from the infliximab multinational psoriatic arthritis controlled trial (IMPACT). Arthritis Rheum 2005; 52:1227-36

17 Chaudhari U, Romano P, Mulcahy LD, Dooley LT, Baker DG, Gottlieb AB. Efficacy and safety of infliximab monotherapy for plaque-type psoriasis: a randomised trial. Lancet 2001;357:1842-7. 
18 Felson DT, Anderson JJ, Boers M, Bombardier C, Furst D, Goldsmith C, et al. American College of Rheumatology preliminary definition of improvement in rheumatoid arthritis. Arthritis Rheum 1995;38:727-35.

19 Clegg DO, Reda DJ, Mejias E, Cannon GW, Weisman MH, Taylor T, et al. Comparison of sulphasalazine and placebo in the treatment of psoriatic arthritis: a Department of Veterans Affairs Cooperative study. Arthritis Rheum 1996;39:2013-20.

20 Fredriksson T, Pettersson U. Severe psoriasis: oral therapy with a new retinoid. Dermatologica 1978;157:238-44.

21 Maini RN, Breedveld FC, Kalden JR, Smolen JS, Davis D, MacFarlane JD, et al. Therapetuic efficacy of multiple intravenous infusions of anti-tumor necrosis factor [alpha] monoclonal antibody combined with low-dose weekly methotrexate in rheumatoid arthritis. Arthritis Rheum 1998;41:1552-63.

22 Crowe W, Kushner I. An immunofluorescent method using Crithidia luciliae to detect antibodies to double-stranded DNA. Arthritis Rheum 1977;20:811-14.

23 Wold RT, Young FE, Tan EM, Farr RS. Deoxyribonucleic acid antibody: a method to detect its primary interaction with deoxyribonucleic acid. Science 1968;161:806-7.

24 Conover WJ. Tests with A.R.E. of 1 or more. In, Practical nonparametric statistics New York, NY, Wiley, 1980:316-20.

25 Ware JE, Kosinski M, Keller SD. Interpretation: norm-based. In: SF-36 physical and mental health summary scales: a user's manual. Boston, MA: The Health Institute, 1994;8(1-8):42.

26 Mease PJ, Ganguly R, Wanke L, Yu E, Singh A. How much improvement in functional status is considered important by patients with active psoriatic arthritis: applying the outcome measures in rheumatoid arthritis clinical trials (OMERACT) group guidelines [abstract]. Ann Rheum Dis 2004;63(suppl I):391.

27 Boumpas DT. Disease-modifying antirheumatic drugs. In: Klippel JH, Crofford $\amalg$, Stone JH, Weyand, CM, eds. Primer on the rheumatic diseases. 12th ed. Atlanta, Georgia: Arthritis Foundation, 2001:233-8.
28 Husted JA, Gladman DD, Farewell VT, Cook RJ. Health-related quality of life of patients with psoriatic arthritis: a comparison with patients with rheumatoid arthritis. Arthritis Care Res 2001;45:151-8.

29 Wong K, Gladman DD, Husted J, Long JA, Farewell VT. Mortality studies in psoriatic arthritis. Results from a single outpatient clinic. Causes and risk of death. Arthritis Rheum 1997;40:1868-72.

30 Gladman DD, Farewell VT, Wong K, Husted J. Mortality studies in psoriatic arthritis. Results from a single outpatient center. Prognostic indicators for death. Arthritis Rheum 1998;41:1103-10.

31 Torre Alonso JC, Rodrigez Perez A, Arribas Castrillo JM, Ballina Garcia J, Riestra Noriega JL, Lopez Larrea C. Psoriatic arthritis (PsA): a clinical, immunological and radiological study of 180 patients. Br J Rheumatol 1991;30:245-50.

32 Sokoll KB, Helliwell PS. Comparison of disability and quality of life in rheumatoid and psoriatic arthritis. J Rheumatol 2001;28:1842-6.

33 Kaltwasser JP, Nash P, Gladman D, Rosen CF, Behrens F, Jones P, et al. Efficacy and safety of leflunomide in the treatment of psoriatic arthritis and psoriasis: a multinational, double-blind, randomized, placebo-controlled clinical trial. Arthritis Rheum 2004;50:1939-50.

34 St Clair EW. Disease-modifying antirheumatic drugs. In: Klippel JH, Crofford $\amalg$, Stone JH, Weyand CM, eds. Primer on the rheumatic diseases, 12th ed.Atlanta, Georgia:Arthritis Foundation, 2001:599-605.

35 Whiting-O'Keefe QE, Fye KH, Sack KD. Methotrexate and histologic hepatic abnormalities: a meta-analysis. Am J Med 1991;90:711-16.

36 Rapp SR, Feldman SR, Exum ML, Fleischer AB, Reboussin DM. Psoriasis causes as much disability as other major medical diseases. J Am Acad Dermatol 1999:41:401-7.

37 Maini R, St Clair EW, Breedveld F, Furst D, Kalden J, Weisman M, et al. Infliximab (chimeric anti-tumour necrosis factor $\alpha$ monoclonal antibody) versus placebo in rheumatoid arthritis patients receiving concomitant methotrexate: a randomized phase III trial. Lancet 1999;354:1932-9.

38 Hanaver SB, Feagan BG, Lichtenstein GR, Mayer LF, Schreiber S, Frederic Colombel J, et al. Maintenance infliximab for Crohn's disease: the ACCENT I randomized trial. Lancet 2002;359:1541-9. 